\title{
Analysis of thrombin generation in plasma
}

Citation for published version (APA):

Kessels, H., Willems, G., \& Hemker, H. C. (1994). Analysis of thrombin generation in plasma. Computers in Biology and Medicine, 24(4), 277-288. https://doi.org/10.1016/0010-4825(94)90024-8

Document status and date:

Published: 01/07/1994

DOI:

10.1016/0010-4825(94)90024-8

Document Version:

Publisher's PDF, also known as Version of record

\section{Please check the document version of this publication:}

- A submitted manuscript is the version of the article upon submission and before peer-review. There can be important differences between the submitted version and the official published version of record.

People interested in the research are advised to contact the author for the final version of the publication, or visit the DOI to the publisher's website.

- The final author version and the galley proof are versions of the publication after peer review.

- The final published version features the final layout of the paper including the volume, issue and page numbers.

Link to publication

\footnotetext{
General rights rights.

- You may freely distribute the URL identifying the publication in the public portal. please follow below link for the End User Agreement:

www.umlib.nl/taverne-license

Take down policy

If you believe that this document breaches copyright please contact us at:

repository@maastrichtuniversity.nl

providing details and we will investigate your claim.
}

Copyright and moral rights for the publications made accessible in the public portal are retained by the authors and/or other copyright owners and it is a condition of accessing publications that users recognise and abide by the legal requirements associated with these

- Users may download and print one copy of any publication from the public portal for the purpose of private study or research.

- You may not further distribute the material or use it for any profit-making activity or commercial gain

If the publication is distributed under the terms of Article $25 \mathrm{fa}$ of the Dutch Copyright Act, indicated by the "Taverne" license above, 


\title{
ANALYSIS OF THROMBIN GENERATION IN PLASMA
}

\author{
Han Kessels, ${ }^{*} \dagger$ George Willems $\ddagger$ and H. Coenraad Hemker $\$$ \\ * Department of Biochemistry, University of Limburg, P.O. Box 616, 6200 MD Maastricht, \\ The Netherlands; and $\ddagger$ Cardiovascular Research Institute, P.O. Box 616, \\ 6200 MD Maastricht, The Netherlands
}

(Received 26 October 1993; received for publication 13 May 1994)

\begin{abstract}
Thrombin is the central enzyme of haemostasis. Information on the production and inhibition of thrombin in plasma is important for evaluating the state of the coagulation system. Measurement of thrombin generation in plasma using small oligopeptide chromogenic substrates gives rise to a signal that not only reflects the enzymatic activity of free thrombin, but also contains a contribution of the complex of thrombin with one of its inhibitors, $a_{2}$-macroglobulin. This paper describes a mathematical procedure to extract from the measured curves the signal due to free thrombin only. The time integral of this free thrombin curve, which we call the thrombin potential, is a parameter which condenses much of the information present in such a curve. Thrombin production from prothrombin can be calculated from the concentration of free thrombin, when the rate constants governing the decay of thrombin are known. It is described how this calculation can be performed, accounting for the consumption of some of the inhibitors of thrombin during coagulation. Measurement of the time integral of the thrombin concentration promises clinical applicability of thrombin generation tests. It is based on the continuous registration of conversion of chromogenic substrate by thrombin during coagulation in plasma. It is shown how the curves obtained by this test can be analysed by a procedure which is analogous to the analysis of curves measured by subsampling from clotting plasma.
\end{abstract}

Blood coagulation Thrombin Plasma Kinetics Inhibition Production

\section{INTRODUCTION}

Thrombin plays a central role in the coagulation system. Its adequate production at the site of a vascular lesion is pivotal in arresting bleeding. The importance of thrombin generation is easily understood from the serious problems that arise in haemophiliacs in which the mechanism of thrombin generation is defective. Even more important is thrombosis, which is the major cause of death in our society (coronary infarction, stroke). Thrombosis can be prevented by inhibition of thrombin generation in one way or another [1].

Initial traces of thrombin are formed by activation of its precursor zymogen prothrombin, upon the exposure to blood or plasma of tissue factor from damaged tissue. These thrombin traces trigger the activation of much larger amounts of prothrombin by feedback activation of blood platelets [2] and the cofactors V and VIII [3-5]. The generation of thrombin is influenced by every type of antithrombotic therapy, as well as by most coagulation disorders [1]. Measurement of the time course of thrombin concentrations in clotting plasma, giving rise to a thrombin generation curve, therefore yields important information about the functioning of the coagulation system [6]. As a useful parameter, summarizing much of the information of a thrombin generation curve, we coined the thrombin potential [7], which is defined as the time integral of the free thrombin concentration. In addition, information on the mechanism whereby the thrombin concentration is affected can be gained by deriving the rate of production of thrombin from thrombin generation curves [8].

$\uparrow$ Present address: Department of Molecular Medicine, Mount Sinai School of Medicine, 1 Gustave Levy Place, Box 1269, New York, NY 10029, U.S.A.

$\S$ Author to whom correspondence should be addressed. 


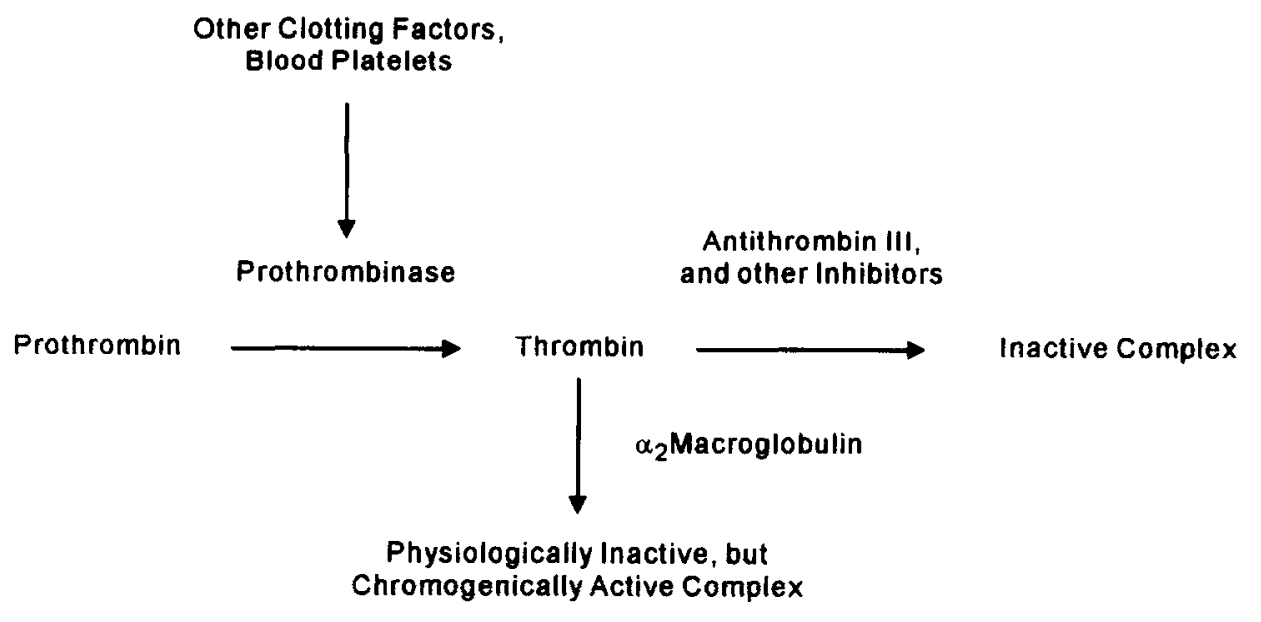

Fig. 1. Reaction scheme of thrombin production and inactivation.

Thrombin generation curves are measured using chromogenic oligopeptide substrates. This assay method is based on the ability of thrombin to cleave off the para-nitroaniline (pNA) group of the substrate, altering its light absorption spectrum [9]. The concentration of thrombin determines the rate of change of optical density at $405 \mathrm{~nm}$. Using this method, thrombin concentrations are determined in subsamples drawn from clotting plasma at timed intervals (usually $30 \mathrm{sec}$ ) [8].

Unfortunately, chromogenic substrates are not completely specific for thrombin. In particular, the physiologically inactive complex of thrombin with one of its inhibitors, $\alpha_{2}$-macroglobulin $\left(\alpha_{2}-\mathrm{M}\right)$, converts small chromogenic substrates almost as well as free thrombin does. This is because $\alpha_{2}$-macroglobulin does not bind the active centre of thrombin, but still impedes the binding and conversion of large, physiologically important (protein) substrates [10-12]. Therefore, the conversion of chromogenic substrate is due to both free thrombin and the $\alpha_{2}$-macroglobulin-thrombin complex. Full interpretation of the raw experimental data necessitates the translation of the measured rates of chromogenic substrate conversion (amidolytic activity) into a time curve of the free thrombin concentration, by subtracting the part of the signal due to $\alpha_{2}$-macroglobulin-thrombin. This also enables calculation of the thrombin potential.

The time course of free thrombin is the result of transient thrombin production from prothrombin on the one hand, and inactivation of thrombin by inhibitors present in plasma on the other (Fig. 1). In order to calculate the time course of thrombin formation from prothrombin, information is therefore needed on thrombin breakdown in plasma. Thrombin is inactivated by several plasma proteins. The main pathway consists of complex formation with antithrombin III (ATIII), but several other inhibitors, such as $\alpha_{1}$-antitrypsin and $\alpha_{2}$-macroglobulin, are active as well $[8,13]$. The concentration of antithrombin III is not much higher than the prothrombin concentration. Thus, a considerable amount of antithrombin III is consumed during blood clotting in a plasma sample [14-16]. The inactivation rate of thrombin is proportional to the product of the thrombin and ATIII concentrations and therefore declines with increasing ATIII consumption [16].

Measuring thrombin generation in subsamples from clotting plasma is not a routine undertaking, as it takes an experienced technician more than an hour of work. We recently described a technique to measure the integral of the thrombin concentration continuously in a cuvette [17]. Since no subsampling is required, the technique has the potential of being automated and used routinely in a hospital laboratory. It is based on the presence of a chromogenic substrate in clotting plasma. Thrombin, while it is being produced and inactivated in the plasma, converts the chromogenic substrate. The rate of conversion of chromogenic substrate at any moment indicates the amount of enzymatic 
activity, so that the optical density vs time curve represents the time integral of the thrombin and $\alpha_{2} \mathrm{M}$-thrombin concentration. Since the concentration of chromogenic substrate used is below its $K_{\mathrm{m}}$, consumption of the substrate results in a lower reaction rate. This, however, can be corrected for mathematically, since the exact concentration of chromogenic substrate can be inferred from the value of the optical density at any time. To analyse the integral thrombin vs time curve, it can be converted in a normal thrombin generation curve by calculating its first derivative. The thrombin potential, however, can be calculated directly from the measured curve.

Thus, analysis of measured thrombin generation curves consists of the following steps.

(1) Correction of the observed amidolytic activities for the $a_{2} \mathbf{M}$-thrombin activities, which results in a time activity curve of free thrombin.

(2) Calculation of the thrombin potential as the area under the latter curve.

(3) Calculation of the rate of thrombin production from the above time activity curve using independent estimates of the thrombin inactivation rate.

Additionally, integral thrombin generation curves can be corrected for substrate consumption, and stripped from the activity due to the $\alpha_{2} \mathrm{M}$-thrombin complex.

\section{METHODS}

\section{Thrombin generation measured by chromogenic assay of subsamples from clotting plasma}

This method is described in full detail in ref. [8]. Briefly, to $240 \mu \mathrm{l}$ of plasma was added $60 \mu \mathrm{l}$ of a buffer (buffer A, $50 \mathrm{mM}$ Tris- $\mathrm{HCl}, 100 \mathrm{mM} \mathrm{NaCl}, 0.5 \mathrm{mg} / \mathrm{ml}$ bovine albumin, $\mathrm{pH}$ 7.35), containing any substance under investigation. Clotting was initiated by addition of $60 \mu \mathrm{l}$ of a solution containing $100 \mathrm{mM} \mathrm{CaCl}_{2}$ and human brain thromboplastin in a suitable dilution. At timed intervals, $10 \mu \mathrm{l}$ subsamples were diluted into a cuvette with $490 \mu \mathrm{l}$ of a buffer (buffer B, $50 \mathrm{mM}$ Tris- $\mathrm{HCl}, 175 \mathrm{mM} \mathrm{NaCl}, 20 \mathrm{mM}$ EDTA, $0.5 \mathrm{mg} / \mathrm{ml}$ bovine albumin, $\mathrm{pH} 7.90$ ), containing $200 \mu \mathrm{M}$ of the chromogenic substrate S2238 (Kabi, Sweden). Amidolysis of the chromogenic substrate in the cuvette was allowed to proceed for approximately $2 \mathrm{~min}$. This reaction was then halted by the addition of $300 \mu \mathrm{l}$ of $1 \mathrm{M}$ citric acid. The precise moments of subsampling and stopping were recorded on a personal computer by means of push-button equipped pipettes. Optical densities were measured at $405 \mathrm{~nm}$ and converted into amidolytic activities ( $\mathrm{mOD} / \mathrm{min}$ ) by dividing by the reaction times. Thus, the result of such a thrombin generation experiment is a series of amidolytic activities with corresponding time points. Figure 2 shows a typical curve of amidolytic activity obtained in pooled normal plasma. The steady end level of this curve is caused by the activity of the $\alpha_{2} \mathbf{M}$-thrombin complex.

\section{Experimental determination of the decay constants of thrombin}

The overall decay constant $k_{\mathrm{tot}}$ of thrombin in plasma can be determined experimentally [16] by addition of thrombin to plasma and measuring the time course of its disappearance. This was done essentially in the same way as described above for measurement of thrombin generation. The amidolytic activities $E(t)$ as obtained in the experiment can be fitted to the following exponential:

$$
E(t)=E(\infty)+(E(0)-E(\infty)) \mathrm{e}^{-k_{\text {tot }} \cdot t}
$$

where $E(0)$ is the initial amidolytic activity, and $E(\infty)$ is the steady end level of amidolytic activity due to the $\alpha_{2} \mathrm{M}$-thrombin complex. The steady end level $E(\infty)$ can reliably be determined by measuring several late points of the curve, and thus needs not be fitted.

\section{Thrombin generation measured by recording the time integral of thrombin in plasma}

This method for measuring thrombin generation pseudo-continuously is described in detail in ref. [17]. In brief, $400 \mu$ l of reptilase defibrinated plasma, $100 \mu$ l of buffer $A$ 


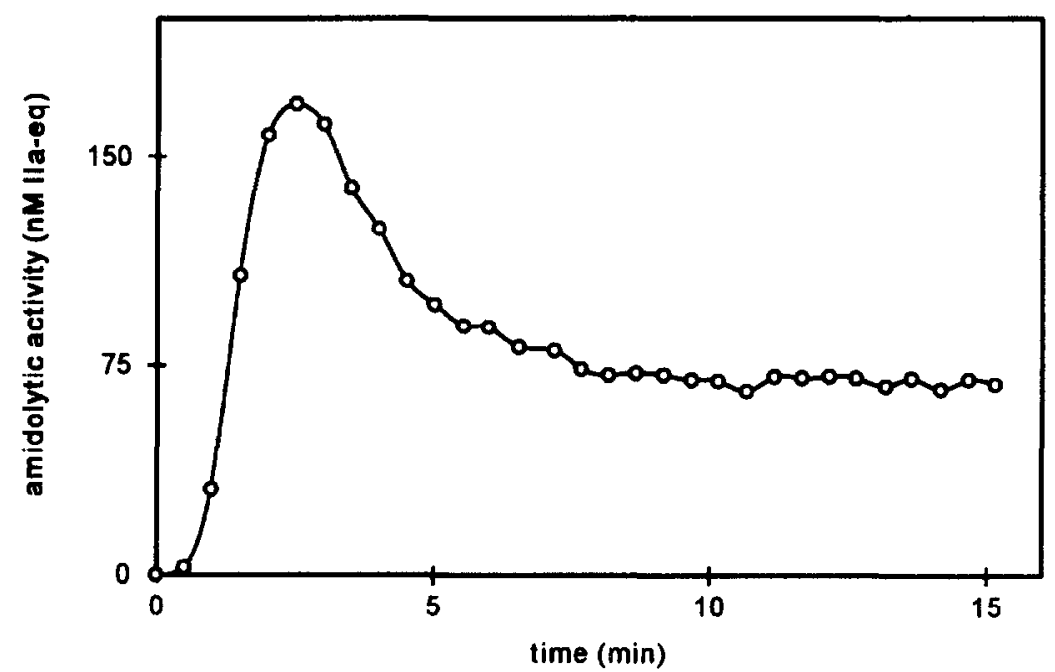

Fig. 2. Time course of the amidolytic activity. The time course was measured in a subsampled thrombin generation experiment carried out as described in normal pooled plasma. Coagulation was triggered at time zero with human brain thromboplastin diluted 240 -fold and $\mathrm{Ca}^{2+}$ $(16.7 \mathrm{mM})$.

containing any substance under investigation, and $60 \mu \mathrm{l}$ of the chromogenic substrate SQ68 (methylmalonyl-methylalanyl-arginyl-pNA, from Serbio, France) were added to a cuvette at $37^{\circ} \mathrm{C}$. The chromogenic substrate SQ 68 was used in these experiments instead of S2238, because of its more suitable kinetic properties, as discussed further below. Clotting was triggered by addition of $40 \mu \mathrm{l}$ of tissue factor in $0.25 \mathrm{M} \mathrm{CaCl}_{2}$. The time course of optical density at $405 \mathrm{~nm}$ was then recorded at a rate of two optical density readings per sec. The chromogenic substrate in the cuvette was continuously converted by the thrombin being produced and broken down. The resulting optical density vs time curve is the time integral of a thrombin generation curve. The final slope of this curve is the result of the amidolytic activity of the $\alpha_{2} \mathrm{M}$-thrombin complex. Figure 3 shows an example of a typical time course of optical density in pooled normal plasma.

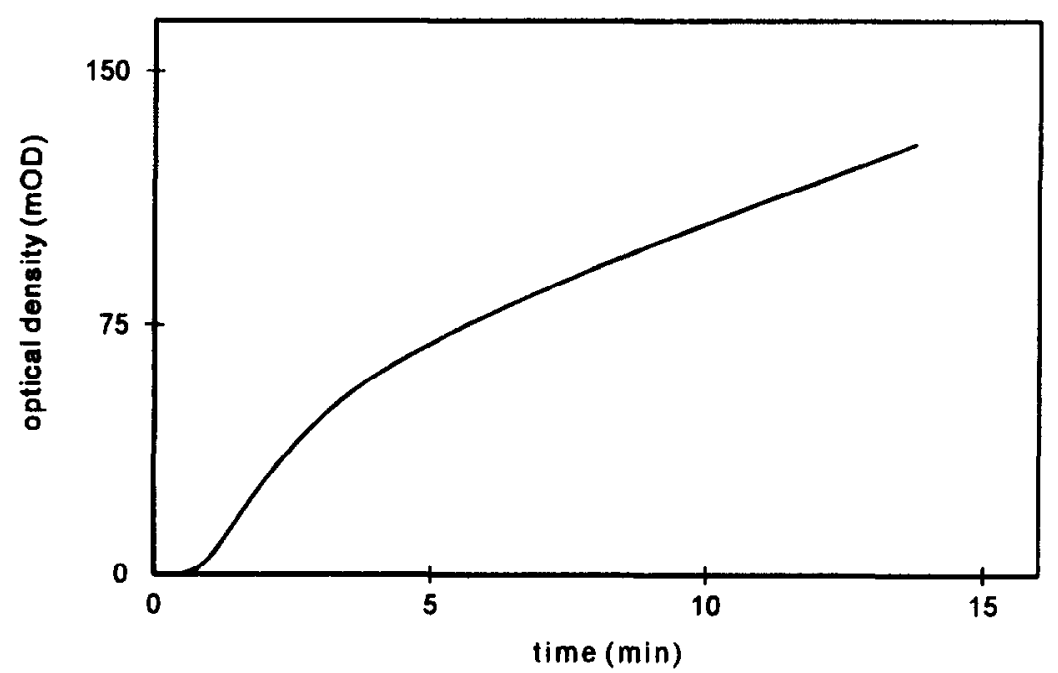

Fig. 3. Continuous measurement of the time integral of the thrombin concentration. The time course of the optical density (in mOD) was measured in an integral thrombin generation experiment carried out as described, in normal pooled plasma. Coagulation was triggered at time zero with human brain thromboplastin diluted 240 -fold and $\mathrm{Ca}^{2+}(16.7 \mathrm{mM})$. The SQ 68 concentration was $500 \mu \mathrm{M}$. 
ANALYSIS

\section{Calculation of the free thrombin concentration from thrombin generation curves}

The experimentally determined amidolytic activity $E$ at time $t$ is the result of both the thrombin concentration $T$ and the concentration of the $a_{2}$-macroglobulin-thrombin complex $M T$. Since the $K_{\mathrm{m}}$ values of thrombin and the $\alpha_{2} \mathrm{M}$-thrombin complex for conversion of S2238 are very much lower than the actual concentration of S2238, the reaction velocity is linear with the thrombin and $\alpha_{2} \mathbf{M}$-thrombin concentrations:

$$
E(t)=k_{\mathrm{cat} 1} \cdot T(t)+k_{\mathrm{cat} 2} \cdot M T(t),
$$

so that

$$
E(t) / k_{\text {cat } 1}=A(t)=T(t)+f \cdot M T(t),
$$

with $A(t)$ as the amidolytic activity converted to $\mathrm{nM}$ of thrombin activity, $k_{\text {catl }}$ and $k_{\text {cat2 }}$ being the catalytic constants for conversion of $\mathbf{S} 2238$ of thrombin and $\alpha_{2} \mathrm{M}$-thrombin, respectively, the $f$ being the reaction rate of substrate conversion by $\alpha_{2} \mathbf{M}$-thrombin relative to the reaction rate of an equal concentration of thrombin, i.e. $f=k_{\mathrm{cat} 2} / k_{\mathrm{cat} 1}$. The value of $f$ has been determined at 0.556 , whereas the value for $k_{\text {cat1 }}$ in our system is $186 \mathrm{sec}^{-1}[8]$.

Thrombin breakdown by $\alpha_{2} \mathrm{M}$ is an apparent first-order process [8], so that the rate at which the complex of thrombin and $\alpha_{2} \mathrm{M}$ forms is linearly dependent on the thrombin concentration:

$$
\frac{\mathrm{d} M T}{\mathrm{~d} t}=k_{2} \cdot T(t)=k_{2}[A(t)-f \cdot M T(t)]
$$

Experimentally, an array of values $A\left(t_{i}\right)$ is measured. Assuming the value of the first-order decay constant for $\alpha_{2} \mathrm{M}\left(k_{2}\right)$ is known, numerical integration of equation (4) yields the values for $M T\left(t_{i}\right)$. When the time between two subsequent samples is not too long (less than about $45 \mathrm{sec}$ for a usual thrombin generation curve), numerical integration using Eulers method gives adequate precision. The array of thrombin concentrations is then calculated by:

$$
T\left(t_{i}\right)=A\left(t_{i}\right)-f \cdot M T\left(t_{i}\right) .
$$

Figure 4 shows a measured time curve of amidolytic activity and the thrombin vs time curve derived from it.

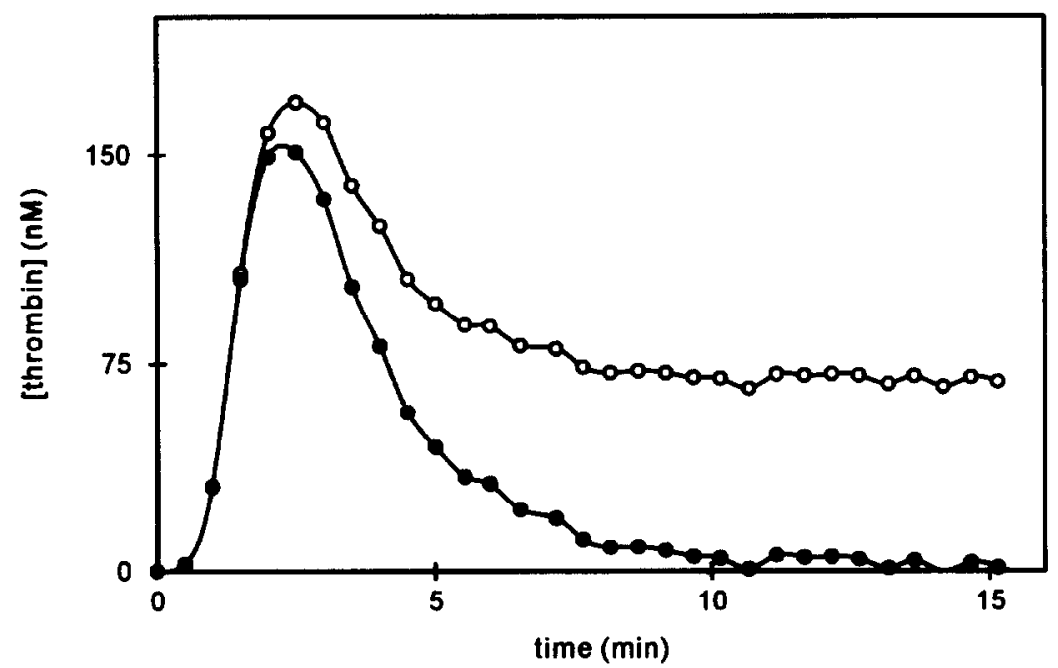

Fig. 4. A thrombin generation curve and the calculated time course of the free thrombin concentration. $O$ : The experimentally determined amidolytic activity; $O$ : free thrombin as calculated from the amidolytic activity and the $a_{2} M$-dependent decay constant $\left(k_{2}\right)$. 
The value of $k_{2}$ can be obtained experimentally as reported [8]. Alternatively, it can be obtained from the amidolytic activity vs time curve, since the complex of $\alpha_{2} \mathrm{M}$ and thrombin has residual amidolytic activity. First, time courses of the free thrombin concentration are calculated from the amidolytic activity values as described above, using a range of values $\kappa$ for $f \cdot k_{2}$. Using equation (4) it is derived that these calculated thrombin concentrations $T_{\kappa}$ are related to the real (but unknown) thrombin concentrations $T$ in the following manner:

$$
T_{\kappa}(t)=T(t)+\left(f \cdot k_{2}-\kappa\right) \int_{0}^{t} \mathrm{e}^{-\kappa(t-\tau)} T(\tau) \mathrm{d} \tau .
$$

If it is assumed that prothrombin conversion has stopped at a time point $t_{0}$ then:

$$
T(t)=T\left(t_{0}\right) \cdot \mathrm{e}^{-\left(k_{1}+k_{2}\right)\left(t-t_{0}\right)}, t \geqslant t_{0} .
$$

If it is further assumed that $k_{1}+k_{2} \gg k_{2}$, then the terms with $\mathrm{e}^{-\left(k_{1}+k_{2}\right)\left(t-t_{0}\right)}$ can be neglected, and $T_{x}$ can be approximated by:

$$
T_{\kappa}(t) \approx\left(f \cdot k_{2}-\kappa\right) C \cdot \mathrm{e}^{-x\left(t-t_{0}\right)}
$$

where

$$
C=\int_{0}^{t_{0}} \mathrm{e}^{-\kappa\left(t_{0}-s\right)} T(s) \mathrm{d} s+\frac{T_{t 0}}{k_{1}+k_{2}-\kappa} .
$$

Thus, $T_{x}(t) / \mathrm{e}^{-\kappa\left(t-t_{0}\right)}$ remains a constant value for a given $\kappa$ after time point $t_{0}$, a property that we used to test the validity of the assumptions. When $\kappa$ is equal to $f \cdot k_{2}$, the value of $T_{\kappa}(t) / \mathrm{e}^{-\kappa\left(t-t_{0}\right)}$ is zero. $T_{x}(t) / \mathrm{e}^{-\kappa\left(t-t_{0}\right)}$ is then plotted as a function of $\kappa$, and $k_{2}$ is calculated from the intersection of this function with the horizontal axis. This intersection can be determined using the bisection method.

\section{Calculation of the rate of prothrombin conversion from time curves of the free thrombin concentration}

The rate of change $(V)$ of the thrombin concentration $(T)$ in plasma is the difference of the rate of thrombin production (= prothrombinase activity, $P$ ) and the rate of thrombin breakdown $(D)$ :

$$
V(t)=\mathrm{d} T / \mathrm{d} t=P(t)-D(t) .
$$

$V(t)$ can be obtained from the series of thrombin concentrations $T(t)$ which are calculated from the measured course of the amidolytic activity $E(t) . D(t)$ is determined from the independently measured thrombin decay constants and the thrombin concentration $T(t)$. The rate of prothrombin conversion $P(t)$ is then calculated by adding $D(t)$ and $V(t)$ for each time point.

Thrombin decay. Thrombin in plasma is inhibited by a number of serine protease inhibitor proteins (I), giving rise to an essentially irreversible complex IT:

$$
\mathrm{T}+\mathrm{I} \rightarrow \mathrm{kT},
$$

where $k^{\prime}$ is the second-order rate constant of thrombin inhibition by the inhibitor.

The rate of formation of IT is then given by the second-order rate equation:

$$
\frac{\mathrm{d} I T}{\mathrm{~d} t}=-\frac{\mathrm{d} I}{\mathrm{~d} t}=k^{\prime} \cdot I(t) \cdot T(t)
$$

Serine protease inhibitors relevant to thrombin breakdown in plasma are antithrombin III (ATII), $\alpha_{2}$-macroglobulin $\left(\alpha_{2} \mathrm{M}\right)$, heparin cofactor II (HCII), and a number of serpins with a relatively unimportant contribution to the anti-thrombin activity $(R)$. The concentration of the most important physiological thrombin inhibitor ATIII is not much 
higher than the prothrombin concentration, so that during the course of coagulation the concentration of ATIII decreases considerably [14-16]. The rate of thrombin breakdown due to ATIII decreases to the same extent, since it is linearly proportional to the ATIII concentration. In the presence of dermatan sulphate, HCII becomes an effective inhibitor, and in this situation consumption of the inhibitor plays an even bigger role, since the plasma concentration of $\mathrm{HCII}$ is about two-thirds of the plasma concentration of prothrombin. In the absence of dermatan sulphate, no inhibitory action of HCII can be detected. The plasma concentration of $\alpha_{2} \mathrm{M}$ is relatively high $(3.5 \mu \mathrm{M})$ and does not decrease significantly during coagulation, nor does the concentration of the group of inhibitors of secondary importance. Therefore, it is reasonable to assume first-order kinetics for the inactivation of thrombin by these inhibitors. The rate of inactivation of thrombin is then given by:

$$
D(t)=\left(k_{1}^{\prime} \cdot A T I I I(t)+k_{4}^{\prime} \cdot H C I I(t)+k_{2}+k_{3}\right) \cdot T(t),
$$

where $k_{2}=k_{2}^{\prime} \cdot \alpha_{2} \mathrm{M}$ and $k_{3}=k_{3}^{\prime} \cdot R, k_{x}^{\prime}$ represent the second-order rate constants for the various inhibitors. The time courses of the ATIII and HCII concentrations are calculated from:

$$
\begin{aligned}
& \frac{\mathrm{d} A T I I I(t)}{\mathrm{d} t}=-k_{1}^{\prime} \cdot A T I I I(t) \cdot T(t) \\
& \frac{\mathrm{d} H C I I(t)}{\mathrm{d} t}=-k_{4}^{\prime} \cdot H C I I(t) \cdot T(t) .
\end{aligned}
$$

The overall first-order decay constant of thrombin in plasma containing the initial concentrations of ATIII and HCII is determined as described in the Methods section. This overall constant can be attributed to the various inhibitors as follows. The $\alpha_{2} \mathrm{M}$ dependent decay constant $k_{2}$ can be inferred directly from a thrombin generation curve, as described above. It can also be determined experimentally as reported [8]. The value of $k_{3}$ has been found to be fairly invariable between individuals at $0.17 \mathrm{~min}^{-1}$ [16]. Since usually the HCII-dependent decay does not play a role, the value of $k_{1}$ is then calculated as $k_{\text {tot }}-k_{2}-k_{3}$. The second-order constant $k_{1}^{\prime}$ for the ATIII-thrombin reaction in the absence of any potentiating substance, such as heparin or a heparin derivative, has been determined at $1.508 \mathrm{~min}^{-1} \cdot \mu \mathrm{M}^{-1}[16]$. This value can then be used to calculate the initial ATIII concentration from the first-order constant $k_{1}$ as follows:

$$
A T I I I(0)=k_{1} / k_{1}^{\prime} \text {. }
$$

Using the decay constants and the initial ATIII concentration thus obtained, equations (12) and (13) can be integrated numerically to calculate the time course of the thrombin decay rate $D(t)$ and the concentrations of the thrombin inhibitor complexes. Again, Eulers method is of sufficient accuracy if the time intervals are not too long $(<45 \mathrm{sec})$. Figure 5 shows $D(t), V(t)$ and $P(t)$ for a typical thrombin generation experiment. Figure 6 shows the time course of the thrombin-inhibitor complexes in the same experiment.

Heparin. Heparin increases the inhibitory capacity of ATIII for thrombin. It acts as a catalyst, since it associates reversibly with ATIII and it is liberated upon formation of the irreversible ATIII-thrombin complex [18]. The complex of ATIII and heparin is a much more effective inhibitor for thrombin than ATIII alone, because the overall association rate of thrombin with the ATIII-heparin complex is three orders of magnitude higher [19].

Heparin binds to ATIII with a $K_{\mathrm{d}}$ of about $180 \mathrm{nM}$ [19], and is normally present in concentrations much lower than the concentration of ATIII, itself present at about $1.5 \mu \mathrm{M}$. Thus, all heparin would be expected to bind to ATIII. However, in plasma the situation is complicated by the competition of ATIII and other plasma proteins for heparin. One example of a heparin binding protein is histidin rich glycoprotein (HRGP), which has a plasma concentration of $\sim 5 \mu \mathrm{M}$ and binds heparin with high affinity $\left(K_{\mathrm{d}}=7 \mathrm{nM}\right)$. 


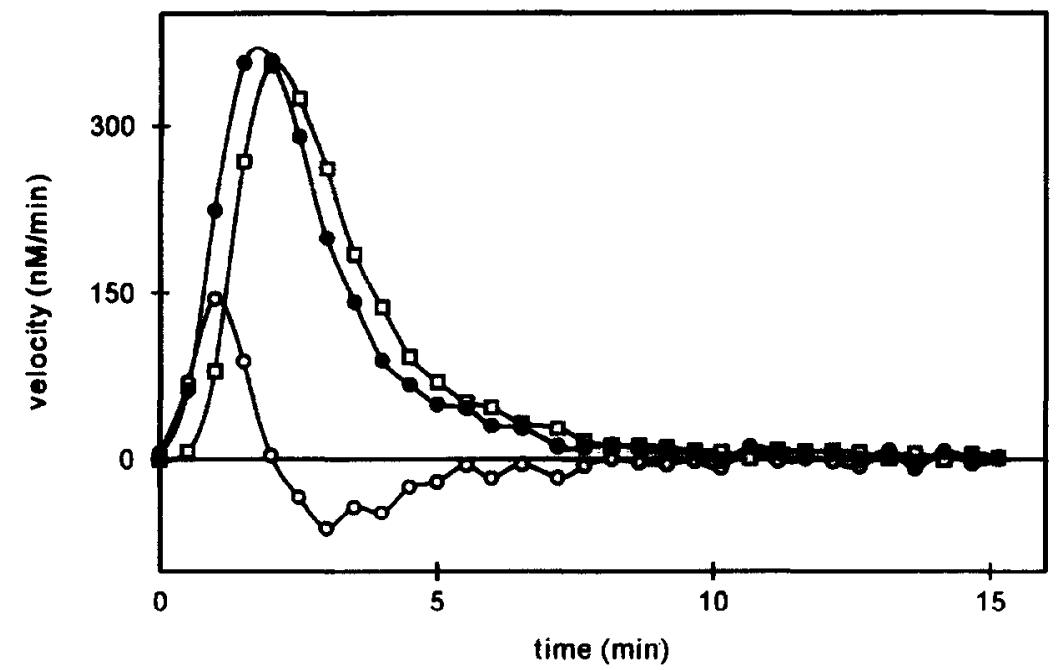

Fig. 5. Velocities of decay and formation of thrombin. The velocity of thrombin decay $(\square)$ was determined from the thrombin generation curve of Fig. 2 and the independently measured thrombin decay constants. Together with the first derivative of the thrombin concentration in time $(O)$, this determines the velocity of prothrombin conversion, also known as the prothrombinase activity (O).

The concentration of the ATIII-heparin complex $(\mathrm{AH})$ in the presence of heparin (H), ATIII, with dissociation constant $K_{\mathrm{Da}}$, and one other heparin binding protein (B) with a dissociation constant $K_{\mathrm{Db}}$ is given by:

with

$$
A H=H \frac{\lambda \cdot A T I I I}{\lambda \cdot A T I I I+K_{\mathrm{Da}}}
$$

$$
\lambda=\frac{K_{\mathrm{Db}}}{B+K_{\mathrm{Db}}} .
$$

In the case of $K_{\mathrm{Da}} \gg \lambda \cdot A T I I I$, as is true for HRGP $\left(K_{\mathrm{Da}} \sim 160 \mathrm{nM}, \lambda \cdot A T I I \sim 2 \mathrm{nM}\right)$, equation (15) reduces to:

$$
A H=\frac{\lambda}{K_{\mathrm{Da}}} H \cdot A T I I I
$$

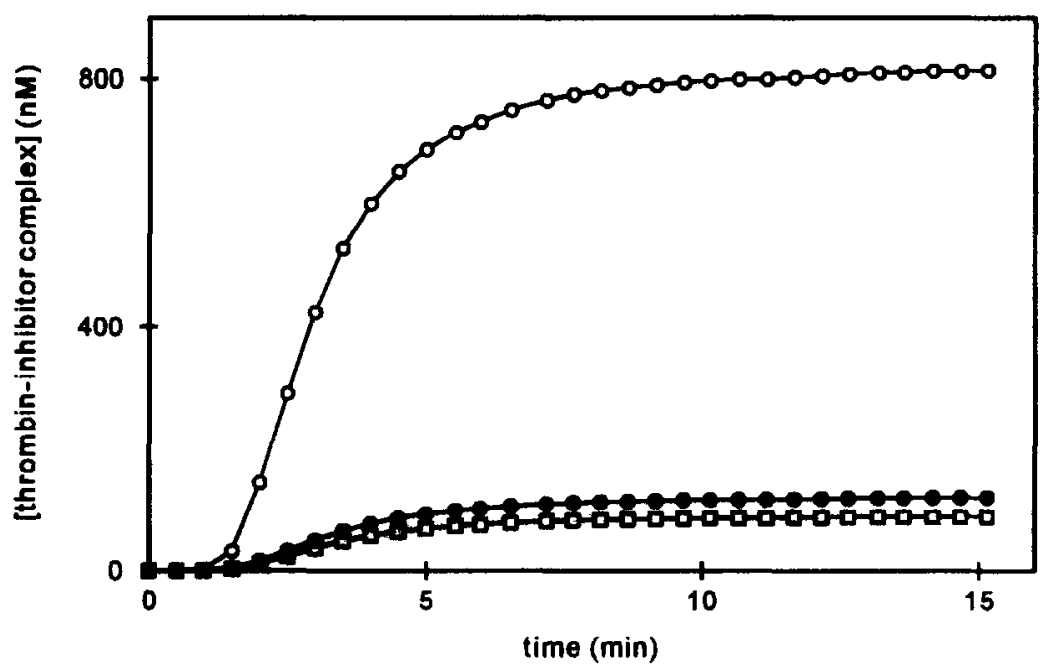

Fig. 6. Thrombin inhibitor complexes. The time course of the concentrations of various thrombin inhibitor complexes as calculated from the thrombin generation curve of Fig. 2 and the measured thrombin decay constants. $O$ : Thrombin-AT III; : thrombin- $\alpha_{2} \mathrm{M} ; \square$ : the complex of thrombin with other minor thrombin inhibitors. 
which shows that the concentration of the ATIII-heparin complex is indeed linearly proportional to the ATIII concentration in the presence of heparin under the above conditions. The presence of several species of heparin binding proteins does not affect this property. Equation (16) is the basis for the definition of the specific antithrombin activity of a heparin. This is defined as the increase of $k_{1}$ caused by $1 \mu \mathrm{g}$ of heparin per $\mathrm{ml}$ plasma normalized to an ATIII level of $1 \mu \mathrm{M}$ [16]. The rate of inhibition of thrombin due to ATIII-heparin $\left(D_{\mathrm{AH}}\right)$ can now be described by:

$$
\begin{aligned}
D_{\mathrm{AH}}(t) & =k_{\mathrm{AH}} \cdot A H(t) \cdot T(t)=k_{\mathrm{AH}} \frac{\lambda}{K_{\mathrm{Da}}} H \cdot A T I I I(t) \cdot T(t) \\
& =k_{1, \text { hep }}^{\prime \prime} \cdot H \cdot A T I I I(t) \cdot T(t) .
\end{aligned}
$$

Assuming that $\Lambda \mathrm{H} \ll \mathrm{ATIII}$, the total rate of inhibition is now given by

$$
\begin{aligned}
D(t) & =\left[\left(k_{1}^{\prime}+k_{1, \text { hep }}^{\prime \prime} \cdot H\right) \cdot A T I I I(t)+k_{4}^{\prime} \cdot H C I I(t)+k_{2}+k_{3}\right] \cdot T(t) \\
& =\left[k_{1, \text { hep }}^{\prime} \cdot A T I I I(t)+k_{4}^{\prime} \cdot H C I I(t)+k_{2}+k_{3}\right] \cdot T(t) .
\end{aligned}
$$

The new second-order rate constant $k_{1, \text { hep }}^{\prime}$, describing thrombin inactivation by ATIII-heparin and by ATIII alone, can then be calculated from the first-order rate constant $k_{1}$ as follows:

$$
k_{1, \text { hpe }}^{\prime}=\left(k_{\mathrm{tot}}-k_{2}-k_{3}\right) / A T I I I(0) \text {. }
$$

The decay of thrombin brought about by heparin cofactor II is normally of no importance. If, however, dermatan sulphate or a related substance is present in plasma, it has to be considered [20]. In such a case, the initial concentration of HCII has to be determined in plasma devoid of ATIII.

\section{Calculation of the time integral of the free thrombin concentration from integral} thrombin generation curves

This assay is based on the continuous conversion of chromogenic substrate by thrombin being produced and inactivated in plasma. However, also the $\alpha_{2} \mathrm{M}$-thrombin complex has the ability to cleave the chromogenic substrate. Calculating the first derivative of the optical density vs time curve, after correcting for consumption of the chromogenic substrate, results in a thrombin generation curve. Consequently, the analysis of such a curve can, in principle, be carried out as described above. It is possible, however, to calculate the thrombin potential directly from the measured optical density vs time curve, bypassing the derivative calculation.

During a measurement, a range of optical density (OD) readings are recorded together with corresponding time values. The concentration of the chromogenic substrate (S) can, at any moment be calculated from the optical density value:

$$
S(t)=S(0)-O D(t) / \varepsilon,
$$

$\varepsilon$ being the molar absorption coefficient of para-nitroaniline at a wavelength of $405 \mathrm{~nm}$.

At any moment, the conversion velocity of the substrate is the sum of the conversion velocitics by thrombin and $\alpha_{2} \mathrm{M}$-thrombin complex. As is evident from Table 1 , the $K_{\mathrm{m}}$

Table 1. Kinetic parameters of SQ 68

\begin{tabular}{llcc}
\hline Enzyme & Conditions & $K_{\mathrm{m}}(\mu \mathrm{M}) \pm$ S.E. & $k_{\text {cat }}\left(\mathrm{sec}^{-1}\right) \pm S . E$. \\
\hline Thrombin & Heated plasma & $819 \pm 19$ & $0.38 \pm 0.002$ \\
Thrombin & Buffer A & $830 \pm 48$ & $0.46 \pm 0.04$ \\
$\alpha_{2}$ M-Thrombin & Serum & $788 \pm 11$ & $0.29 \pm 0.01$ \\
\hline
\end{tabular}

The kinetic parameters for thrombin conversion of the chromogenic substrate SQ 68 were measured by measuring the rate of hydrolysis of SQ 68 values in the range of $0-2000 \mu \mathrm{M}$ by thrombin in a concentration of $100 \mathrm{nM}$, at $37^{\circ} \mathrm{C}$. The $k_{\text {cat }}$ and $K_{\mathrm{m}}$ values were extracted from the substrate vs reaction rate curves using a non-linear fit procedure. 


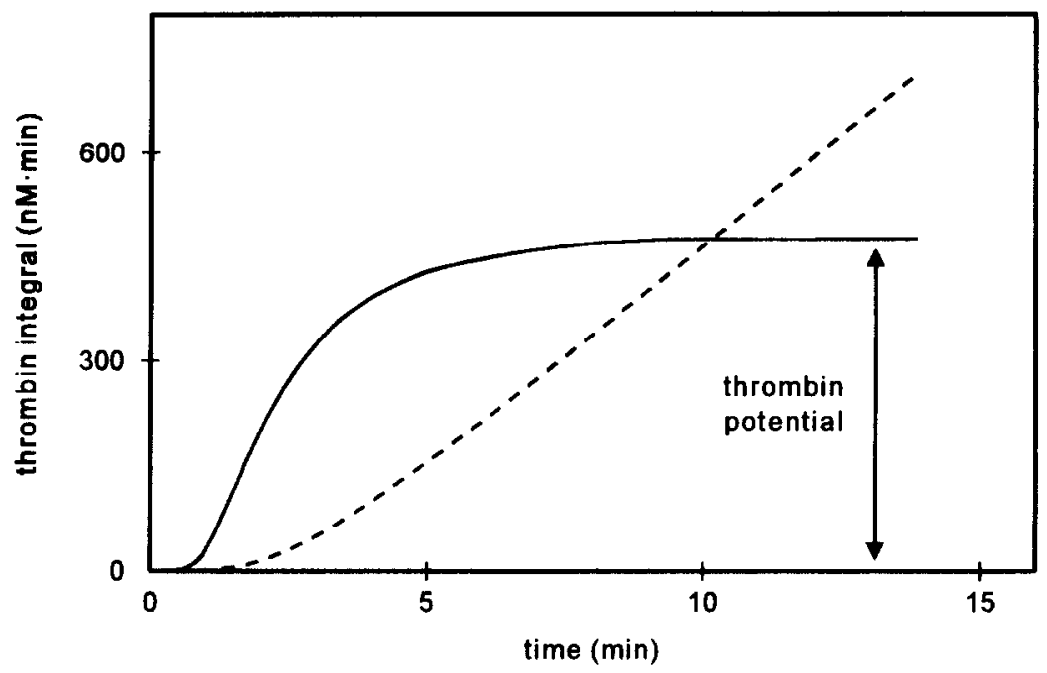

Fig. 7. Time integral of the free thrombin concentration. The time course of the time integral of the thrombin concentration (-) as calculated from the time course of optical density measured during an integral thrombin generation experiment. The dashed line (---) shows the time course of the integral of the $\alpha_{2}$-macroglobulin-thrombin concentration.

for SQ 68 by thrombin and $\alpha_{2} \mathrm{M}$-thrombin are about equal, whereas their $k_{\text {cat }}$ values differ:

$$
-\frac{\mathrm{d} S}{\mathrm{~d} t}=k_{\mathrm{cat} 1} \cdot T(t) \cdot \frac{S(t)}{S(t)+K_{\mathrm{m}}}+k_{\mathrm{cat} 2} \cdot \alpha_{2} M(t) \cdot \frac{S(t)}{S(t)+K_{\mathrm{m}}},
$$

which resolves into:

$$
A P(t)=T P(t)+f \cdot M P(t)=\frac{S(0)-S(t)+K_{\mathrm{m}}(\ln S(0)-\ln S(t))}{k_{\text {cat } 1}},
$$

with

$$
T P(t)=\int_{0}^{t} T(\tau) \mathrm{d} \tau
$$

and

$$
M P(t)=\int_{0}^{t} \alpha_{2} M(\tau) \mathrm{d} \tau,
$$

with $f$ again equal to $k_{\text {cat }} / k_{\text {cat1 }}$. This equation accounts for the consumption of chromogenic substrate during the measurement.

Integration of equation (4) gives the relationship between the time integral of the $\alpha_{2} \mathrm{M}$ concentration, $M P(t)$, and the time integral of the thrombin concentration, $T P(t)$ :

$$
\begin{aligned}
\frac{\mathrm{d} M P(t)}{\mathrm{d} t} & =M(t)=k_{2} \cdot \int_{0}^{t} T(\tau) \mathrm{d} \tau=k_{2} \cdot T P(t) \\
& =k_{2} \cdot(A P(t)-f \cdot M P(t)) .
\end{aligned}
$$

Thus the array of values for $M P(t)$ can again be obtained by numerical integration of this equation, and the values of the thrombin integral can be calculated as:

$$
T P\left(t_{i}\right)=A P\left(t_{i}\right)-f \cdot M P\left(t_{i}\right) .
$$

Figure 7 shows an integral thrombin curve derived from a time curve of optical density. The thrombin potential now is the final level of the integral thrombin curve, as shown in the figure. 


\section{SUMMARY}

Measurement of thrombin generation in clotting plasma has undergone a revival during the last decade spurred by the synthesis of chromogenic oligopeptide substrates in the mid 1970s. Thrombin, being the central enzyme in haemostasis, is able to convey much useful information about the coagulation process [1]. Extracting this information from thrombin generation curves is often non-trivial, however. The first hurdle is the amidolytic activity of the complex of thrombin and $\alpha_{2}$-macroglobulin, which adds considerably to the signal measured both in normal and integral thrombin generation experiments [10-12]. This paper describes a mathematical procedure to strip the experimental data from their unwanted clothing. Much of the useful information from both normal and integral thrombin generation curves can be concentrated in one parameter, the thrombin potential, which is the time integral of the free thrombin concentration, and can easily be calculated from curves of the free thrombin concentration [7]. It is sensitive to all known types of anticoagulant therapy. The time course of the rate of thrombin production, indicating the activity of the prothrombinase complex, can be calculated once the rate of inactivation of thrombin in plasma is known. Altered thrombin concentrations can in this way be shown to be due to increased inhibition of thrombin or to decreased formation of thrombin. It is shown how the time course of thrombin inactivation is inferred from the decay constants of thrombin for various thrombin inhibitors. For some of these inhibitors, namely ATIII and HCII, consumption of the inhibitor has to be taken into account. It is further shown how the rate of thrombin decay can be described in the presence of heparin.

The development of an automatable method of measuring integral thrombin generation curves has created the opportunity for the thrombin generation test to enter into the realm of clinical laboratory analysis [17]. Since, in this assay procedure, a chromogenic substrate is present during thrombin generation and decay in plasma, the time integral of thrombin and $\alpha_{2} \mathrm{M}$-thrombin concentrations is recorded. The part of the signal due to $\alpha_{2} \mathrm{M}$-thrombin can be subtracted in a procedure analogous to the calculation used for normal thrombin generation curves. The resulting curve contains all the information that is present in a normal thrombin generation curve. The inevitable consumption of the substrate during the clotting process is accounted for mathematically. The thrombin potential can be inferred from an integral thrombin generation curve without the need for calculating its derivative.

All calculations presented in this article have been implemented in several computer programs (for IBM compatibles) which can be obtained from the authors.

\section{REFERENCES}

1. H. C. Hemker, Thrombin generation, an essential step in haemostasis and thrombosis, Haemostasis and Thrombosis, L. Bloom et al., Eds. Churchill Livingstone, Edinburgh (1993).

2. M. G. Davey and E. F. Luscher, Actions of thrombin and other proteolnytic enzymes on blood platelets, Nature 216, 857-858 (1967).

3. S. I. Rapaport, S. Schiffman, M. J. Patch and S. B. Ames, The importance of activation of antiheamophilic globulin and proaccelerin by traces of thrombin in the generation of intrinsic prothrombinase activity, Blood 21, 221-236 (1963).

4. R. W. Colman, The effect of proteolytic enzymes on bovine factor V. Kinetics of activation and inactivation by bovine thrombin, Biochemistry 4, 1438-1444 (1969).

5. J. Rosing, G. Tans, J. W. P. Govers-Riemslag, R. F. A. Zwaal and H. C. Hemker, The role of phospholipids and factor Va in the prothrombinase complex, J. biol. Chem. 255, 274-283 (1980).

6. R. Biggs and R. G. Macfarlane, Human Blood Coagulation and its Disorders. Blackwell Scientific, Oxford (1953).

7. H. C. Hemker, S. Wielders and S. Béguin, The thrombin potential. A parameter to assess the effect of antithrombotic drugs on thrombin generation. Fraxiparine, 2nd International Symposium. Recent Pharmacological and Clinical Data, H. Bounameaux, M. Samama and J. tenCate, pp. 89-101. Schattauer, Stuttgart (1990).

8. H. C. Hemker, G. M. Willems and S. A. Béguin, A computer assisted method to obtain the prothrombin activation velocity in whole plasma independent of thrombin decay processes, Thromb. Haemost. 56, 9-17 (1986).

9. H. C. Hemker, Handbook of Synthetic Substrates for the Coagulation and Fibrinolytic System, p. 27 Martinus Nijhoff, Boston (1983).

10. A. J. Barret and P. M. Starkey, The interaction of $\alpha_{2}$-macroglobulin with proteinases, Biochem. J. 133, 709-715 (1973). 
11. H. Rinderknecht, R. M. Feling and M. C. Geokas, Effect of $\alpha_{2}$-macroglobulin in some kinetic parameters of trypsin, Biochim. biophys. Acta 377, 150-165 (1975).

12. A. M. Fischer, J. Tapon-Bretaudière, A. Bros and F. Josso, Respective roles of antithrombin III and $a_{2}$-macroglobulin in thrombin inactivation, Thromb. Haemost. 45, 51-54 (1981).

13. R. W. Carrel, P. B. Christey and D. R. Boswell, Serpins: antithrombin and other inhibitors of coagulation an fibrinolysis. Evidence from amino acid sequences, Thrombosis and Haemostasis, M. Verstraete, J. Vermylen, R. Lijnen and J. Arnout, Eds, p. 1. Leuven University Press, Leuven (1987).

14. A. Hensen and E. A. Loeliger, Antithrombin III, its metabolism and its function in blood coagulation, Thromb. Haemost, Suppl. 1 (1963).

15. M. K. Fagerhol and U. Abilgaard, Immunological studies on human antithrombin III. Influence of age, sex and use of oral anticonceptives on serum concentration, Scand. J. Haemat. 7, 10-17 (1970).

16. S. Béguin, H. Kessels, F. Dol and H. C. Hemker, The consumption of antithrombin III during coagulation, its consequences for the calculation of prothrombinase activity and the standardisation of heparin activity, Thromb. Haemost. 68, 136-142 (1992).

17. H. C. Hemker, S. Wielders, H. Kessels and S. Béguin, Continuous registration of thrombin generation in plasma, its use for the determination of the endogenous thrombin potential, Thromb. Haemost. 70, 617624 (1993).

18. S. T. Olson and J. D. Shore, Transient kinetics of heparin-catalyzed protease inactivation by antithrombin III. The reaction step limiting heparin turnover in thrombin neutralization, J. biol. Chem. 261, 13 15113159 (1986)

19. S. T. Olson and J. D. Shore, Demonstration of a two-step reaction mechanism for inhibition of $\alpha$-thrombin by antithrombin III and identification of the step affected by heparin, J. biol. Chem. 257, 14 891-14895 (1982).

20. D. M. Tollefsen, Activation of heparin cofactor Il by heparin and dermatan sulfate, N. Rev. Fr. Hemat. 26, 233-237 (1984).

About the Author-HAN Kessels graduated from the Faculty of Medicine of Maastricht, The Netherlands, in 1988 and received a Ph.D. degree in Biochemistry in 1993 at the University of Limburg. He now holds a postdoctoral fellowship at Mount Sinai Medical School in the Division of Molecular Medicine, New York (Lab. Prof. Dr Y. Nemerson)

About the Author-GEORGE M. WILLEMS, Ph.D., graduated from the Department of Mathematics and Physics, University of Utrecht. He joined the Medical Faculty of the University of Linburg in 1974. His major interest is in the field of coagulation reactions, with emphasis on protein-lipid interactions and mathematical modelling.

About the Author-H. Coenraad Hemker, M.D., Ph.D. (University of Amsterdam), is chairman of the Department of Biochemistry at the Medical Faculty of the University of Limburg and Professor of Internal Medicine at the University of Leiden. Since 1963 he has been active in the field of physiological and pathological chemistry of blood coagulation. 